\title{
Extração e exportação de nutrientes pelo híbrido de mamona Savana: II - Micronutrientes
}

\section{Nutrients extraction and exportation by Savana castor bean hybrid: II - Micronutrients}

\author{
Carlos Alexandre Costa Crusciol ${ }^{1 *}$; Martha Santana do Nascimento ${ }^{2}$; \\ Adalton Mazetti Fernandes ${ }^{3}$; Maurício Dutra Zanotto ${ }^{4}$
}

\begin{abstract}
Resumo
Informações sobre extração e exportação de micronutrientes em híbridos de mamona de porte baixo, bem como os períodos de maior exigência de cada um deles, são de suma importância para o manejo correto da adubação. Objetivou-se com este trabalho avaliar a extração e a exportação de micronutrientes pelo híbrido de mamona Savana, de porte baixo, no cultivo de safra e safrinha. Os experimentos foram conduzidos na safra 2005/2006 e na safrinha de 2006 em Latossolo Vermelho distroférrico. Utilizou-se o delineamento em blocos casualizados, com quatro repetições. As parcelas foram constituídas pelas épocas de coletas de plantas, as quais foram realizadas aos 17, 31, 45, 59, 73, 97 e 120 dias após a emergência (DAE) durante a safra e aos 17, 31, 45, 59, 80, 100 e 120 DAE na safrinha. Em ambas as safras a ordem extração de micronutrientes pelo híbrido Savana foi: $\mathrm{Fe}>\mathrm{Mn}>\mathrm{Zn}>\mathrm{B}>\mathrm{Cu}>\mathrm{Mo}$, mas com quantidades maiores no cultivo de safra. A época de maior absorção de Mo e Zn durante a safra e de Fe na safrinha ocorre aos 80 DAE, porém os demais micronutrientes são absorvidos em maiores taxas entre os 50 e 65 DAE. Na safra a produtividade de grãos, a extração e a exportação de nutrientes do solo são maiores, mas a extração e exportação por tonelada de grãos têm menor variação entre as épocas de cultivo. Em média $50 \%$ do $\mathrm{Zn}$ absorvido ao longo do ciclo e $60 \%$ do $\mathrm{Cu}$ extraído na safrinha são exportados com os grãos, mas para os demais micronutrientes a proporção exportada é inferior a 40\%. Palavras-chave: Ricinus communis, nutrição mineral, curvas de absorção, taxas de absorção, produtividade de grãos
\end{abstract}

\begin{abstract}
Information about micronutrients extraction and exportation by castor bean hybrids of short stature, and the periods of highest demand for each micronutrient, are most importance for correct management to fertilization. This study aimed to evaluate the micronutrients extraction and exportation by Savana hybrid castor bean, on season and out-of-season growing. The experiments were conducted during season of 2005/2006 and out-of-season of 2006 in an Oxisol. The experimental design was a randomized block with four replications. The plots were consisted by harvest times of plants, which were carried out at 17, 31, 45, 59, 73, 97 and 120 days after emergence (DAE) during the season and at 17, 31, 45, 59,$80 ; 100$ and $120 \mathrm{DAE}$ in the out-of-season. In both seasons the order of micronutrients extraction
\end{abstract}

1 Prof. Titular do Dept $^{\circ}$ de Produção Vegetal, Agricultura, Faculdade de Ciências Agronômicas, FCA, Universidade Estadual Paulista, UNESP, Botucatu, SP. Bolsista de Produtividade em Pesquisa pelo CNPq. E-mail: crusciol@fca.unesp.br

$2 \mathrm{Dr}^{\mathrm{a}}$ em Agronomia, Agricultura, Pesquisadora da N\&S Agriconsult. E-mail: martha@agriconsult.com.br

3 Doutorando em Agronomia, Agricultura, Faculdade de Ciências Agronômicas, FCA, Universidade Estadual Paulista, UNESP, Botucatu, SP. Bolsista Fapesp. E-mail: adaltonfernandes@hotmail.com

4 Prof. Dr. Assistente do Dept ${ }^{\mathbf{o}}$ de Produção Vegetal, Agricultura, Faculdade de Ciências Agronômicas, FCA, Universidade Estadual Paulista, UNESP, Botucatu, SP. E-mail: zanotto@fca.unesp.br

* Autor para correspondência 
by hybrid Savanna is: $\mathrm{Fe}>\mathrm{Mn}>\mathrm{Zn}>\mathrm{B}>\mathrm{Cu}>\mathrm{Mo}$, but with larger amounts of season cultivation. The time of greatest $\mathrm{Zn}$ and Mo absorption during the season and the Fe in out-of-season occurs at 80 DAE, although the other micronutrients are absorbed at higher rates between 50 and 65 DAE. In season the yield, nutrients extraction and exportation from soil are higher than out-of-season, but the nutrients extraction and exportation per ton show less variation between growing seasons. Fifty percent of zinc and $60 \%$ of $\mathrm{Cu}$ uptaken, on average, in out-of-season is exported with grains, but for the other micronutrients the proportion exported with grains is less than $40 \%$.

Key words: Ricinus communis, mineral nutrition, absorption curves, absorption rates, yield

\section{Introdução}

A maioria das informações existentes na literatura sobre absorção e exportação de nutrientes pela cultura da mamona (Ricinus communis L.) são restritas apenas aos macronutrientes (CANECCHIO FILHO; FREIRE, 1958; NAKAGAWA; NEPTUNE, 1971). Apesar dos micronutrientes serem absorvidos em pequenas quantidades, os mesmos, são fundamentais para o crescimento e o desenvolvimento das culturas (KIRKBY; RÖMHELD, 2007), sendo que a falta de qualquer um deles causa perdas significativas de produtividade. Em mamona, a deficiência de boro (B) causa necrose progressiva do ápice das plantas, superbrotamento e queda de folhas (PAULO et al., 1989), sendo que a deficiência de outros micronutrientes como ferro (Fe), manganês (Mn) e cobre $(\mathrm{Cu})$, reduzem o crescimento e a matéria seca da parte aérea e do sistema radicular (LANGE et al., 2005). Em solos com baixos teores de $\mathrm{Cu}$, a redução na produtividade da mamoneira chega a ser superior a 50\% (SANTOS et al., 2004). Entretanto essa oleaginosa é mais tolerante a deficiência de zinco (Zn) (FERREIRA et al., 2004; LANGE et al., 2005), seja por sua baixa necessidade ou pela alta capacidade de extração desse nutriente do solo.

Nas décadas de 80 e 90 vários estudos sobre nutrição mineral e adubação com micronutrientes foram realizados nessa oleaginosa (HOCKING, 1982; PAULO et al., 1989; SOUZA; NATALE, 1997). Entretanto, na maioria dos trabalhos foram utilizadas cultivares de características genotípicas diferentes dos híbridos modernos cultivados atualmente, ou seja, cultivares de ciclo vegetativo longo, porte alto e maturação desuniforme.
Assim, devido ao aumento recente do cultivo dessa oleaginosa nas últimas safras (CHAVES et al., 2009), utilizando híbridos de porte baixo adaptados aos sistemas de produção mecanizados e com alto potencial produtivo (SILVA et al., 2010), novos estudos sobre nutrição mineral e adubação com micronutrientes têm sido desenvolvidos com essa cultura (LANGE et al., 2005; SEVERINO et al., 2006; CHAVES et al., 2009; DANTAS JÚNIOR et al., 2010). Entretanto, ainda não existem dados na literatura sobre extração e exportação de micronutrientes em híbridos de mamona de porte baixo, os quais, provavelmente são mais exigentes que as cultivares tradicionais, uma vez que os níveis de produtividade são maiores e o ciclo é menor. Em função dessas características, possivelmente a demanda dos híbridos modernos por micronutrientes num curto espaço de tempo é muito superior que àquela observada nas cultivares tradicionais de ciclo longo e crescimento indeterminado.

Dessa forma, tornam-se necessários estudos atualizados sobre absorção e exportação de micronutrientes em híbridos de mamona de porte baixo para que sejam realizadas adubações equilibradas nessa cultura, pois, o ótimo crescimento das culturas depende do suprimento dos nutrientes exigidos pelo tecido em crescimento, no exato momento da demanda específica (DORDAS et al., 2001). Assim, com as curvas de absorção de micronutrientes será possível verificar as épocas em que são demandadas as maiores quantidades desses elementos (ORLANDO FILHO; ROSSETTO; CASAGRANDE, 2001), bem como as quantidades que são removidas da área de cultivo pelos grãos. Essas informações permitem manejar de forma 
eficiente as adubações visando reduzir perdas e aumentar a eficiência de uso dos fertilizantes, auxiliando no estabelecimento de adubações de restituição, para a manutenção da fertilidade do solo.

Com base nisto, o presente trabalho objetivou avaliar a extração e a exportação de micronutrientes pelo híbrido de mamona Savana, de porte baixo, no cultivo de safra e safrinha.

\section{Material e Métodos}

Os experimentos foram conduzidos na Fazenda Experimental Lageado no município de Botucatu, $\mathrm{SP}\left(48^{\circ} 26^{\prime} \mathrm{W}\right.$ e $22^{\circ} 51^{\prime} \mathrm{S}$ e $740 \mathrm{~m}$ de altitude). O solo do local foi classificado como Latossolo Vermelho distroférrico, textura média, manejado há seis anos no sistema plantio direto. Durante a condução dos experimentos foram determinadas diariamente as temperaturas máximas e mínimas e a precipitação pluvial (Figura 1).

Figura 1. Precipitação (】), temperaturas máxima (-) e mínima (-) registradas durante a condução dos experimentos e posicionamento do momento da emergência, florescimento e colheita do híbrido de mamona Savana na safra 2005/06 e na safrinha 2006.

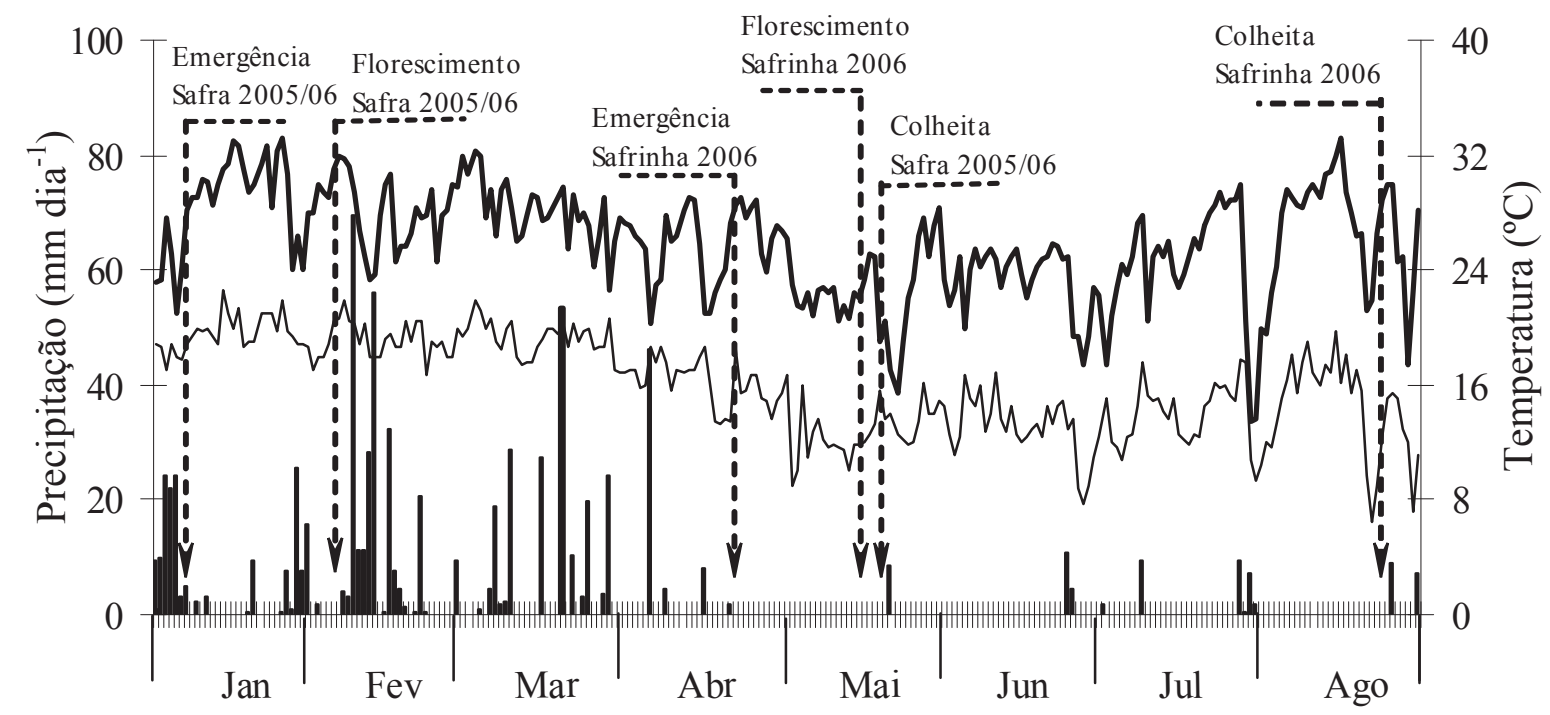

Fonte: Elaboração dos autores.

$\mathrm{O}$ delineamento experimental utilizado foi $\mathrm{o}$ de blocos casualizados, com quatro repetições. As parcelas foram constituídas pelas épocas de coletas de plantas, as quais foram realizadas aos 17, 31, 45, 59, 73, 97 e 120 dias após a emergência (DAE), durante a safra, e aos $17,31,45,59,80,100$ e 120 DAE, durante o cultivo de safrinha. As parcelas foram constituídas de seis fileiras de plantas de cinco $\mathrm{m}$ de comprimento. Considerou-se como bordadura, as duas fileiras de plantas da extremidade da parcela e $1 \mathrm{~m}$ de ambos os lados.
Antes da instalação dos experimentos realizaram-se amostragens na camada de 0-0,20 $\mathrm{m}$ para determinação das características químicas do solo (RAIJ et al., 2001), cujos resultados para safra foram: $\mathrm{MO}=24,0 \mathrm{~g} \mathrm{dm}^{-3} ; \mathrm{pH}\left(\mathrm{CaCl}_{2} 0,01\right.$ $\left.\mathrm{mol} \mathrm{L}{ }^{-1}\right)=5,1 ; \mathrm{P}($ resina $)=16,0 \mathrm{mg} \mathrm{dm}^{-3} ; \mathrm{K}^{+}, \mathrm{Ca}^{2+}$, $\mathrm{Mg}^{2+}, \mathrm{H}+\mathrm{Al}$ e $\mathrm{CTC}=1,5,31,17,38$ e $87 \mathrm{mmol}_{\mathrm{c}}$ $\mathrm{dm}^{-3}$, respectivamente, saturação por bases de $56 \%$ e teores de $\mathrm{B}, \mathrm{Cu}, \mathrm{Fe}, \mathrm{Mn}$ e $\mathrm{Zn}$, respectivamente, de $0,30,6,1,42,5,9$, e $1,1 \mathrm{mg} \mathrm{dm}^{-3}$. Na safrinha, os resultados de análise de solo foram: $\mathrm{MO}=36,0$ 
$\mathrm{g} \mathrm{dm}^{-3} ; \mathrm{pH}\left(\mathrm{CaCl}_{2} 0,01 \mathrm{~mol} \mathrm{~L}^{-1}\right)=5,1 ; \mathrm{P}$ (resina) $=28,0 \mathrm{mg} \mathrm{dm}{ }^{-3} ; \mathrm{K}^{+}, \mathrm{Ca}^{2+}, \mathrm{Mg}^{2+}, \mathrm{H}+\mathrm{Al}$ e $\mathrm{CTC}=$ $1,3,26,13,51$ e $92 \mathrm{mmol}_{\mathrm{c}} \mathrm{dm}^{-3}$, respectivamente, saturação por bases de $45 \%$ e teores de $\mathrm{B}, \mathrm{Cu}, \mathrm{Fe}$, $\mathrm{Mn}$ e $\mathrm{Zn}$, respectivamente, de $0,27,6,5,38,6,2$, e $1,2 \mathrm{mg} \mathrm{dm}^{-3}$.

Para a implantação dos experimentos, realizouse a dessecação das plantas espontâneas das áreas com glyphosate (1,8 kg do i.a ha-1) e a semeadura da mamona na safra foi realizada no dia 23/12/2005 sobre palhada de aveia, e na safrinha a semeadura foi no dia 03/04/2006 sobre palhada de milho. A semeadura da mamona foi realizada com semeadoraadubadora da marca Semeato (Personale Drill modelo 13), utilizando-se 1,1 sementes por metro de sulco (25.000 plantas ha $\left.{ }^{-1}\right)$, no espaçamento entre linhas de 0,45 metros. Em ambos os experimentos, utilizaram-se sementes tratadas com fungicida carboxin-thiran (60 g $100 \mathrm{~kg}^{-1}$ de sementes do i.a.) e

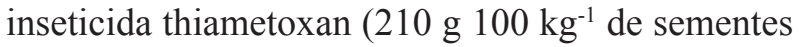
do i.a.), do híbrido comercial Savana.

O híbrido Savana é de porte baixo, ciclo semiprecoce (160 dias), floresce por volta dos 42 dias após a emergência (DAE), apresenta $75 \%$ de flores femininas, boa rusticidade, altura média de 1,60 $\mathrm{m}$, frutos indeiscentes, boa debulha, produtividade média de $1.600 \mathrm{~kg} \mathrm{ha}^{-1}$, recomendado para colheita mecanizada.

A adubação de semeadura foi realizada com base na análise de solo e nas recomendações de Savy Filho et al. (1999), aplicando-se $250 \mathrm{~kg} \mathrm{ha}^{-1}$ do formulado NPK 08-28-16+4,5\% de S + 0,5\% de Zn. No experimento realizado na safra $(2005 / 2006)$ a emergência ocorreu em 08/01/2006 e na safrinha em 23/04/06. Em cobertura foram aplicados $50 \mathrm{~kg}$ $\mathrm{ha}^{-1}$ de $\mathrm{N}$ na forma de nitrato de amônio aos $20 \mathrm{DAE}$, quando as plantas apresentavam-se com 4-5 folhas totalmente expandidas. A distribuição do adubo foi realizada sobre a superfície do solo ao lado e aproximadamente $10 \mathrm{~cm}$ das fileiras de plantas.

Para o controle de plantas daninhas foram realizadas aplicações dos herbicidas setoxidim
(184 $\mathrm{g} \mathrm{ha}^{-1}$ do i.a.) e clorimurom etílico (20 $\mathrm{g} \mathrm{ha}^{-1}$ do i.a.). Realizaram-se aplicações dos fungicidas procimidona (150 $\mathrm{g} \mathrm{ha}^{-1}$ do i.a.) e iprodiona (150 $\mathrm{g}$ ha $^{-1}$ do i.a.) para o controle de mofo cinzento (Botrytis ricini) no início e 20 dias após o florescimento.

Em cada época de coleta, retiraram-se de cada parcela a parte aérea de quatro plantas seqüenciadas de uma fileira, que tinham de todos os lados plantas competitivas e que apresentavam-se visualmente sem sintomas de doenças. As plantas amostradas foram separadas em caule, folhas e estruturas reprodutivas, lavadas e secadas em estufa de circulação forçada de ar a $65^{\circ} \mathrm{C}$ por $168 \mathrm{~h}$ e pesadas. Os dados de matéria seca (MS) associados às épocas de coleta de plantas foram usados para a obtenção das curvas de acúmulo de MS durante o ciclo.

Após pesadas, as amostras foram moídas em moinho tipo Wiley e determinaram-se os teores de micronutrientes, segundo metodologia descrita por Malavolta, Vitti e Oliveira (1997). Com os dados de teores de micronutrientes e acúmulo de MS, calcularam-se as quantidades de micronutrientes acumuladas em cada parte da planta e na parte aérea. As taxas de acúmulo de micronutrientes na parte aérea e nas estruturas reprodutivas foram obtidas por meio da derivada primeira da equação ajustada da quantidade acumulada na parte aérea e nas estruturas reprodutivas, respectivamente.

A colheita da safra e da safrinha foi realizada aos 120 DAE. Para a avaliação da produtividade de grãos, foram colhidas, manualmente, as plantas contidas na área útil da parcela, ou seja, em 4 linhas de $3 \mathrm{~m}$ de comprimento. Os cachos foram trilhados, os grãos pesados e, posteriormente, calculou-se a produtividade de grãos em $\mathrm{kg} \mathrm{ha}^{-1}$. Os valores da massa de 100 grãos e a produtividade de grãos foram padronizados para o teor de água de $80 \mathrm{~g} \mathrm{~kg}^{-1}$ (base úmida). Na safra a produtividade de grãos foi de $2.582 \mathrm{~kg} \mathrm{ha}^{-1}$, e na safrinha a produtividade foi de $494 \mathrm{~kg} \mathrm{ha}^{-1}$. A exportação de micronutrientes foi obtida a partir dos dados de produtividade e dos teores de micronutrientes nos grãos. 
Os dados foram submetidos à análise de variância. As médias dos teores de micronutrientes em cada parte da planta foram comparadas pelo teste $\mathrm{t}$ (DMS) a 5\% de probabilidade. Os efeitos das épocas de coletas de plantas para as variáveis acúmulo de MS, teor e acúmulo de micronutrientes foram avaliados mediante análise de regressão, com auxílio do "software" SigmaStat e os gráficos foram elaborados no SigmaPlot 10.0.

\section{Resultados e Discussão}

Em ambas as safras, o acúmulo de MS no caule, folhas e parte aérea foi pequeno até o início do florescimento (31 DAE), porém, após esse período, os acúmulos de MS intensificaram-se em proporções diferentes entre as safras (Figura 2). Os caules acumularam MS até próximo ao final do ciclo em ambas as safras, mas o acúmulo de MS nas folhas aumentou até aos 60 DAE na safrinha e até aos 73 DAE na safra, sofrendo reduções nas fases seguintes devido à senescência e queda de folhas (Figura 2). Outros autores também observaram senescência foliar e abscisão de folhas em cultivares de mamona de porte anão, em época semelhante à observada no presente estudo (CHAVES et al., 2009; DANTAS JÚNIOR et al., 2010), demonstrando que o máximo desenvolvimento das folhas no híbrido Savana ocorre por volta dos 60 a $70 \mathrm{DAE}$, à semelhança do que ocorre em cultivares e híbridos de porte baixo.

Nos primeiros 20 a 30 dias após o florescimento houve o desenvolvimento simultâneo do caule, folhas e estruturas reprodutivas (Figura 2). Entretanto, a partir dos 60 DAE a intensidade de acumulação de MS nas estruturas reprodutivas foi maior, provavelmente, devido ao direcionamento de parte dos fotoassimilados dos outros tecidos para o desenvolvimento deste órgão, já que os grãos em formação atuam como drenos de fotoassimilados ocasionando, desta forma, redução da área e MS foliar (TAIZ; ZEIGER, 2004; DANTAS JÚNIOR et al., 2010).

Na parte aérea o acúmulo de MS intensificou-se após o florescimento (31 DAE), em ambas as safras, em função do crescimento intenso das estruturas reprodutivas (Figura 2). Verificou-se que houve acúmulo de MS na parte aérea até o final do ciclo, quando as plantas atingiram os acúmulos máximos de $6.904 \mathrm{~kg} \mathrm{ha}^{-1}$ na safra e $1.139 \mathrm{~kg} \mathrm{ha}^{-1}$ na safrinha. $\mathrm{O}$ menor crescimento e o menor acúmulo de MS na safrinha foram reflexos da menor disponibilidade hídrica nessa época de cultivo (Figuras 1 e 2).

No cultivo de safra, em que houve maior disponibilidade hídrica (Figura 1), os teores foliares de B foram superiores aos obtidos no caule e nas estruturas reprodutivas, o que não foi observado na safrinha (Tabelas 1 e 2). Os maiores teores foliares de B na safra, devem-se ao fato que esse micronutriente apresenta transporte unidirecional no xilema, via corrente transpiratória e grande imobilidade no floema (MALAVOLTA, 1980). Assim, como as folhas apresentam maior transpiração, esse nutriente acumula-se em maiores proporções neste órgão. Em ambos os cultivos os teores foliares de B aumentaram até por volta dos 80 DAE, mas nas estruturas reprodutivas o teor desse nutriente diminuiu linearmente, devido ao efeito de diluição causado pelo aumento intenso da MS (Tabelas 1 e 2 e Figura 2). Na safra, o aumento intenso na MS do caule causou a diluição do teor de B, o qual diminuiu até por volta aos 90 DAE, enquanto na safrinha, como os incrementos na MS de caule foram menores, os teores aumentaram até os 76 DAE (Figura 2 e Tabelas 1 e 2). Verificou-se que os teores foliares de $\mathrm{B}$ em determinados períodos do ciclo ficaram abaixo da faixa de 35 a $91 \mathrm{mg} \mathrm{kg}^{-1}$ obtida por Souza e Natale (1997) em mamoneira adubada com diferentes doses de B e Zn. 
Figura 2. Acúmulo de matéria seca no caule (a), folhas (b), estruturas reprodutivas (c), parte aérea (d), e taxas de acúmulo de matéria seca nas estruturas reprodutivas (e) e na parte aérea (f) do híbrido de mamona Savana na safra 2005/06 e na safrinha 2006. **: significativo a $1 \%$ de probabilidade pelo teste $\mathrm{F}$.
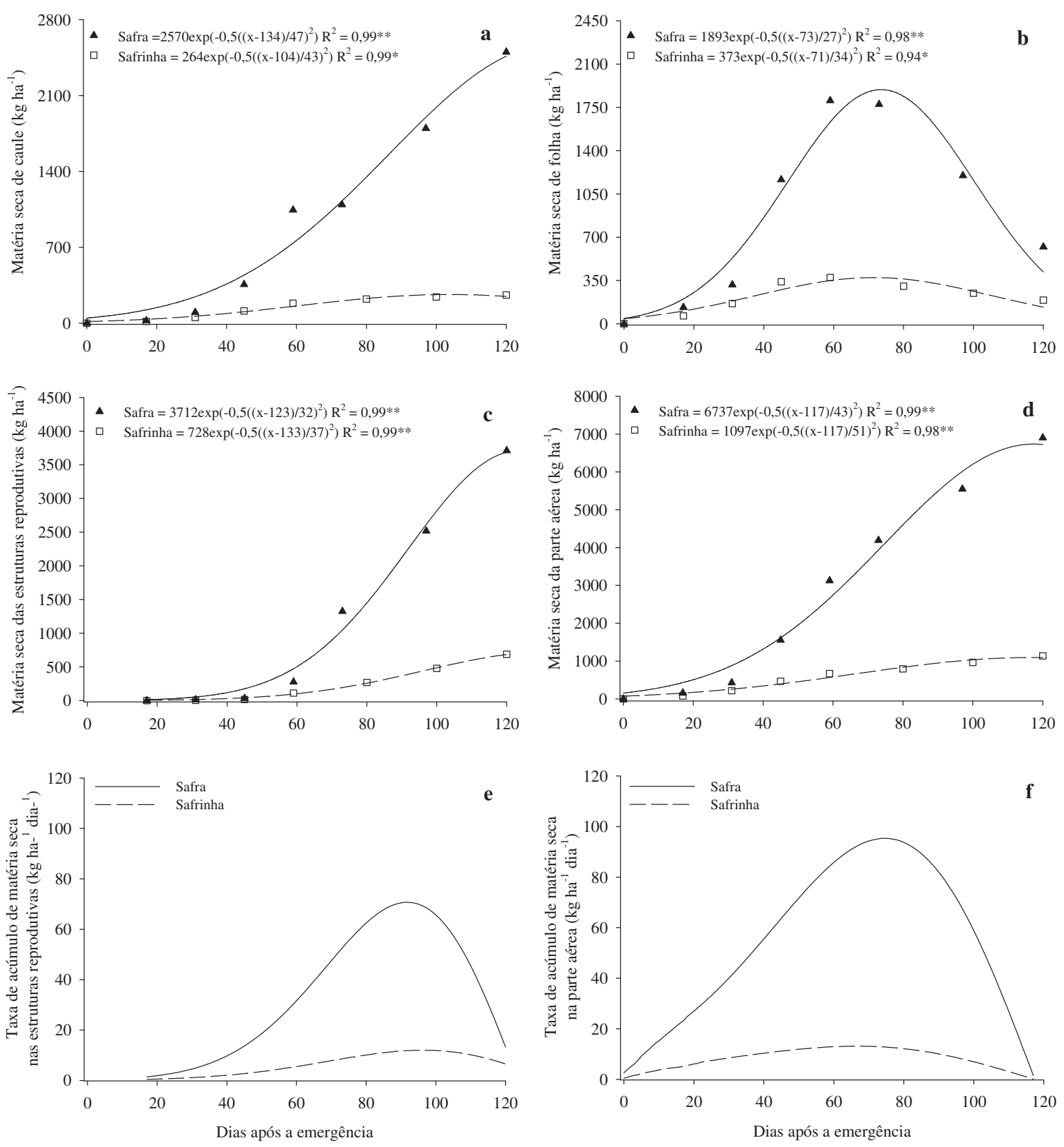

Fonte: Elaboração dos autores. 
Tabela 1. Teores de micronutrientes no caule, folhas e estruturas reprodutivas do híbrido de mamona Savana na safra 2005/06.

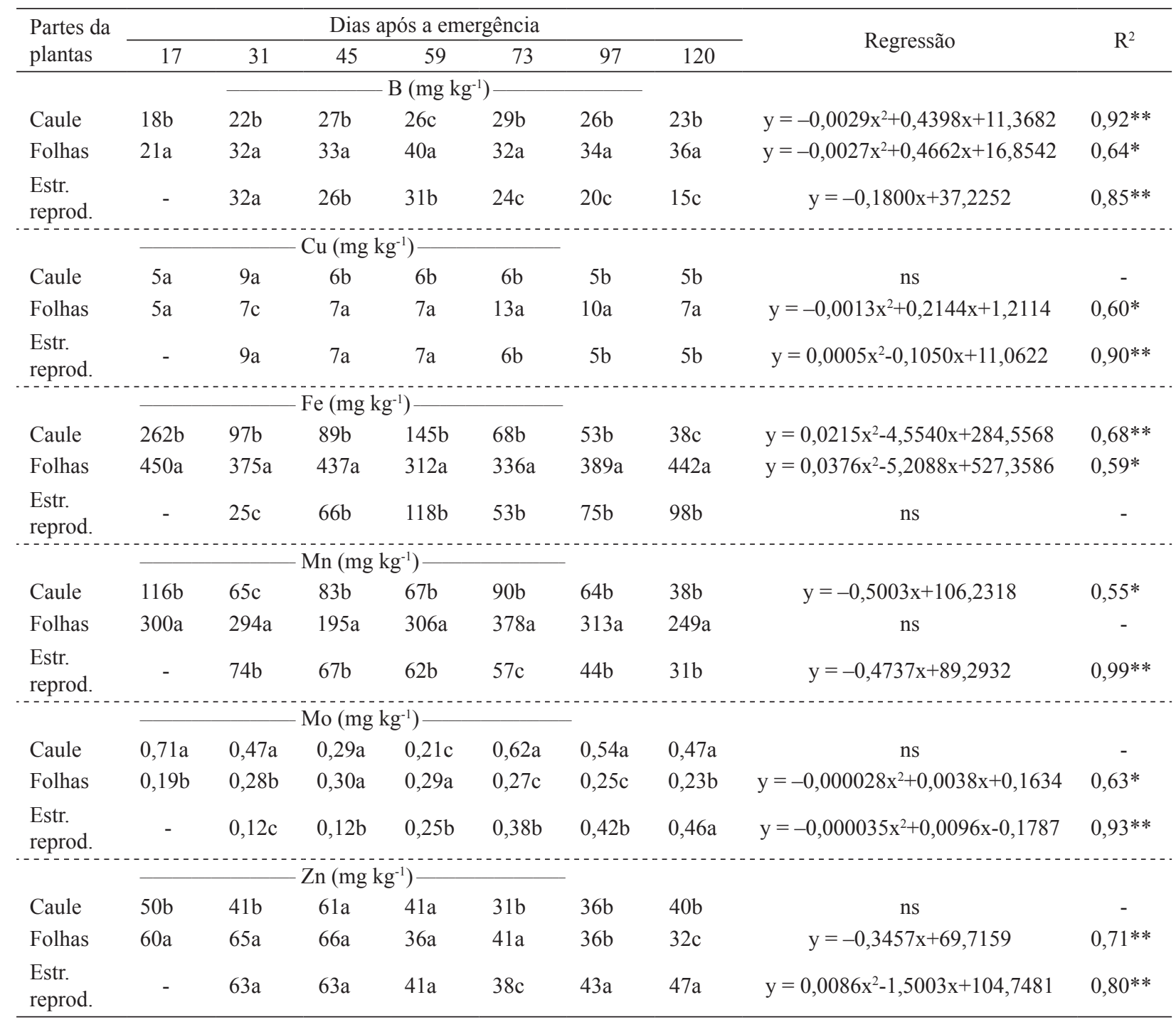

Médias seguidas de letras iguais, nas colunas, não diferem pelo teste t (DMS) a $5 \%$ de probabilidade. ns: Não significativo. * e **Significativo pelo teste $\mathrm{F}$, a 5 e $1 \%$ de probabilidade, respectivamente.

Fonte: Elaboração dos autores.

Os maiores teores de $\mathrm{Cu}$ e $\mathrm{Fe}$ ocorreram nas folhas, cujos valores para o $\mathrm{Cu}$ durante a safra aumentaram desde a emergência até os 82 DAE, e a partir dos 47 DAE na safrinha (Tabelas 1 e 2). Na safra, os teores foliares de Fe diminuíram até os $69 \mathrm{DAE}$, ou seja, durante o período de crescimento intenso da MS foliar, mas na safrinha os teores foliares desse nutriente foram crescente até os 100 DAE (Tabelas 1 e 2 e Figura 2). Em ambas as safras, os teores de $\mathrm{Cu}$ no caule mantiveram-se estáveis durante o ciclo, mas na safra os teores de Fe reduziram com o aumento da MS até os 100 DAE, sendo que na safrinha, os teores aumentaram a partir dos 47 DAE. Nas estruturas reprodutivas, os teores de $\mathrm{Cu}$ e Fe aumentaram durante a safrinha, mas na safra os teores de $\mathrm{Cu}$ diminuíram, devido ao efeito de diluição causado pelo crescimento intenso dessas estruturas nessa época de cultivo. 
Tabela 2. Teores de micronutrientes no caule, folhas e estruturas reprodutivas do híbrido de mamona Savana na safrinha 2006.

\begin{tabular}{|c|c|c|c|c|c|c|c|c|c|}
\hline \multirow{2}{*}{$\begin{array}{l}\text { Partes da } \\
\text { plantas }\end{array}$} & \multicolumn{7}{|c|}{ Dias após a emergência } & \multirow{2}{*}{ Regressão } & \multirow{2}{*}{$\mathrm{R}^{2}$} \\
\hline & 17 & 31 & 45 & 59 & 73 & 97 & 120 & & \\
\hline & & & $\bar{z}$ & $3(\mathrm{mg} \mathrm{kg}$ & & & & & \\
\hline Caule & $37 \mathrm{~b}$ & $44 a$ & $20 \mathrm{ab}$ & $17 \mathrm{~b}$ & $17 \mathrm{~b}$ & $18 \mathrm{~b}$ & $18 \mathrm{a}$ & $y=0,0047 x^{2}-0,8682 x+55,3443$ & $0,75^{* *}$ \\
\hline Folhas & $10 \mathrm{a}$ & $22 \mathrm{c}$ & $17 \mathrm{~b}$ & $25 \mathrm{a}$ & $36 \mathrm{a}$ & $27 \mathrm{a}$ & $19 \mathrm{a}$ & $y=-0,0051 x^{2}+0,7983 x-1,9750$ & $0,72 * *$ \\
\hline \multirow[t]{2}{*}{$\begin{array}{l}\text { Estr. } \\
\text { reprod. }\end{array}$} & - & $26 b$ & $23 \mathrm{a}$ & $23 \mathrm{a}$ & $20 \mathrm{~b}$ & $18 \mathrm{~b}$ & $17 \mathrm{a}$ & $y=-0,0995 x+28,3782$ & $0,98^{* *}$ \\
\hline & & & $\mathrm{Cu}(\mathrm{mg} \mathrm{k}$ & & & & & & \\
\hline Caule & $6 a$ & $4 \mathrm{c}$ & $7 \mathrm{a}$ & $4 \mathrm{c}$ & $5 \mathrm{~b}$ & $5 b$ & $5 \mathrm{~b}$ & ns & - \\
\hline Folhas & $6 a$ & $8 \mathrm{a}$ & $7 \mathrm{a}$ & $6 \mathrm{~b}$ & $7 \mathrm{a}$ & $9 \mathrm{a}$ & $12 \mathrm{a}$ & $y=0,0010 x^{2}-0,0933 x+8,0822$ & $0,81^{* *}$ \\
\hline \multirow[t]{2}{*}{$\begin{array}{l}\text { Estr. } \\
\text { reprod. }\end{array}$} & - & $7 \mathrm{~b}$ & $6 \mathrm{~b}$ & $7 \mathrm{a}$ & $6 a b$ & $9 \mathrm{a}$ & $11 \mathrm{a}$ & $y=0,0011 x^{2}-0,1174 x+9,0770$ & $0,89^{* *}$ \\
\hline & & & $\mathrm{Fe}(\mathrm{mg} \mathrm{k}$ & & & & & & \\
\hline Caule & $79 b$ & $103 b$ & $55 \mathrm{~b}$ & $53 b$ & $99 \mathrm{c}$ & $160 \mathrm{c}$ & $221 \mathrm{c}$ & $y=0,0303 x^{2}-2,847 x+131,292$ & $0,93 * *$ \\
\hline Folhas & $206 a$ & $269 a$ & $287 \mathrm{a}$ & $317 \mathrm{a}$ & $564 a$ & $545 \mathrm{a}$ & $425 \mathrm{a}$ & $y=-0,0435 x^{2}+8,981 x+26,437$ & $0,76^{* * *}$ \\
\hline \multirow[t]{2}{*}{$\begin{array}{l}\text { Estr. } \\
\text { reprod. }\end{array}$} & - & $88 \mathrm{~b}$ & $93 b$ & $58 \mathrm{~b}$ & $171 b$ & $268 b$ & $366 b$ & $y=0,0454 x^{2}-3,530 x+147,668$ & $0,97^{* *}$ \\
\hline & & & $\mathrm{Mn}(\mathrm{mg})$ & & & & & & \\
\hline Caule & $68 \mathrm{~b}$ & $46 b$ & $66 \mathrm{~b}$ & $45 \mathrm{~b}$ & $55 \mathrm{~b}$ & $85 \mathrm{~b}$ & $116 b$ & $y=0,0145 x^{2}-1,5098 x+88,299$ & $0,89^{* *}$ \\
\hline Folhas & $163 a$ & $218 \mathrm{a}$ & $256 \mathrm{a}$ & $250 \mathrm{a}$ & $286 a$ & $278 \mathrm{a}$ & $270 \mathrm{a}$ & $y=-0,0214 x^{2}+3,867 x+111,049$ & $0,95^{* *}$ \\
\hline \multirow[t]{2}{*}{$\begin{array}{l}\text { Estr. } \\
\text { reprod. }\end{array}$} & - & $54 \mathrm{~b}$ & $56 b$ & $60 \mathrm{~b}$ & $62 b$ & $65 b$ & $68 b$ & $y=0,1580 x+49,2926$ & $0,98^{* *}$ \\
\hline & & & Mo (mg & & & & & & \\
\hline Caule & $0,56 \mathrm{a}$ & $0,31 \mathrm{a}$ & $0,42 \mathrm{a}$ & $0,28 \mathrm{~b}$ & $0,53 \mathrm{a}$ & $0,53 \mathrm{a}$ & $0,53 \mathrm{a}$ & ns & - \\
\hline Folhas & $0,06 \mathrm{~b}$ & $0,12 \mathrm{c}$ & $0,23 \mathrm{c}$ & $0,28 \mathrm{~b}$ & $0,26 \mathrm{~b}$ & $0,25 b$ & $0,24 b$ & $y=-0,00005 x^{2}+0,0082 x-0,062$ & $0,91 * *$ \\
\hline \multirow[t]{2}{*}{$\begin{array}{l}\text { Estr. } \\
\text { reprod. }\end{array}$} & - & $0,23 b$ & $0,37 \mathrm{~b}$ & $0,55 \mathrm{a}$ & $0,06 \mathrm{c}$ & $0,06 \mathrm{c}$ & $0,04 \mathrm{c}$ & ns & - \\
\hline & & & $\mathrm{Zn}(\mathrm{mg} \mathrm{k}$ & & & & & & \\
\hline Caule & $58 \mathrm{a}$ & $40 \mathrm{c}$ & $41 \mathrm{c}$ & $25 \mathrm{~b}$ & $27 \mathrm{~b}$ & $29 \mathrm{a}$ & $31 \mathrm{a}$ & $y=0,0064 x^{2}-1,1006 x+72,443$ & $0,88^{* *}$ \\
\hline Folhas & $54 \mathrm{a}$ & $64 \mathrm{a}$ & $56 a$ & $41 \mathrm{a}$ & $35 \mathrm{a}$ & $28 \mathrm{a}$ & $21 b$ & $y=-0,3960 x+67,955$ & $0,89^{* *}$ \\
\hline $\begin{array}{l}\text { Estr. } \\
\text { reprod. }\end{array}$ & - & $51 b$ & $49 b$ & $42 \mathrm{a}$ & $25 \mathrm{~b}$ & $28 \mathrm{a}$ & $32 \mathrm{a}$ & $y=0,0054 x^{2}-1,0779 x+82,357$ & $0,86^{* *}$ \\
\hline
\end{tabular}

Médias seguidas de letras iguais, nas colunas, não diferem pelo teste t (DMS) a 5\% de probabilidade. ns: Não significativo. $*$ e **Significativo pelo teste $\mathrm{F}$, a 5 e $1 \%$ de probabilidade, respectivamente.

Fonte: Elaboração dos autores.

Tanto na safra como na safrinha, os teores foliares de Mn foram superiores aos do caule e das estruturas reprodutivas (Tabelas 1 e 2). Na safrinha, os teores de Mn aumentaram até os 90 DAE, mas no período de safra os teores foram semelhantes ao longo do ciclo. Na safra, o maior acúmulo de MS ocasionou redução nos teores de Mn no caule e estruturas reprodutivas, mas na safrinha os teores aumentaram, já que o acúmulo de MS foi menor (Tabelas 1 e 2 e Figura 2). Os maiores teores foliares de $\mathrm{Fe}, \mathrm{Mn}$ e $\mathrm{Cu}$ em comparação as demais estruturas das plantas, estão relacionados com suas funções no metabolismo, principalmente na transferência de elétrons durante o processo fotossintético. $\mathrm{O} F$ o Mn participam da síntese da clorofila, sendo que o Fe também faz parte da ferredoxina, enquanto que o Mn participa do fotossistema II, e a maior parte do $\mathrm{Cu}$ está ligada a plastocianina, estruturas essas, presentes nos cloroplastos e que atuam na fotossíntese (DECHEN; NACHTIGALL, 2006). 
O Mo foi o micronutriente que ocorreu em menores teores nos tecidos da planta, sendo que, durante a maior parte do ciclo, esse nutriente foi observado em maiores teores no caule (Tabelas 1 e 2). Isso ocorre porque grande parte do Mo encontrase na enzima nitrato redutase das raízes e caule das plantas, a qual catalisa a redução do íon $\mathrm{NO}_{3}^{-}$a $\mathrm{NO}_{2}^{-}$ (DECHEN; NACHTIGALL, 2006). No caule, o teor de Mo não foi alterado ao longo do ciclo, o que também foi observado nas estruturas reprodutivas durante a safrinha. Os teores de Mo nas folhas, em ambas as safras, e nas estruturas reprodutivas, durante a safra, aumentaram de forma quadrática no decorrer do ciclo, alcançando os teores máximos foliares aos 68 e 82 DAE, para a safra e safrinha, respectivamente (Tabelas 1 e 2).

Nas últimas avaliações, os teores de $\mathrm{Zn}$ nas estruturas reprodutivas, durante a safra, foram superiores aos obtidos nos demais órgãos das plantas (Tabelas 1 e 2). Apesar do Zn ser considerado pouco móvel nas plantas (MALAVOLTA, 1980), esse elemento apresenta certa mobilidade nos tecidos, sendo que sua translocação ocorre, principalmente durante a senescência (WOOD et al., 1986), o que pode explicar em parte a redução linear dos teores foliares desse nutriente, principalmente durante as fases finais do ciclo (Tabelas 1 e 2). Nas estruturas reprodutivas, os teores de $\mathrm{Zn}$ também diminuíram, devido ao efeito diluição causado pelo aumento da MS (Tabelas 1 e 2 e Figura 2).

Com relação à absorção de micronutrientes, constatou-se que os acúmulos no caule de $\mathrm{B}, \mathrm{Cu}$, $\mathrm{Mn}$, Mo e $\mathrm{Zn}$ foram pequenos nos primeiros 30 DAE, em ambas as safras (Figuras 3a, 4a, 6a, 7a e 8a). Após os 30 DAE, houve intensificação dos acúmulos desses nutrientes, nos caules no período de safra, porém na safrinha os incrementos foram pequenos, em decorrência da menor MS de caule na safrinha (Figuras 2a). O padrão de acumulação de Fe no caule diferiu entre as safras, pois, na safra, o acúmulo foi crescente desde a emergência, enquanto que na safrinha os incrementos foram pequenos nos primeiros 30 DAE (Figura 5a).
Na safra, o acúmulo de $\mathrm{B}, \mathrm{Cu}$, Mo e $\mathrm{Zn}$ no caule aumentou até o final do ciclo, enquanto que o Fe e Mn foram acumulados até os 105 e 95 DAE, respectivamente (Figuras 3a, 4a, 5a, 6a, 7a e 8a). Já na safrinha, a acumulação de Fe e Mn no caule ocorreu até os $120 \mathrm{DAE}$, enquanto que os demais micronutrientes tiveram acúmulos crescentes até entre 85 e 100 DAE. Os micronutrientes que foram acumulados em maiores quantidades no caule durante a safra foram Mn, Zn e Fe, entretanto, na safrinha o Fe foi mais acumulado que o Mn e o $\mathrm{Zn}$ (Figuras 5a, 6a e 8a). Constatou-se que, para todos os micronutrientes, as quantidades acumuladas no caule durante a safra foram superiores as da safrinha, devido à menor intensidade de chuvas na safrinha, que refletiu em menor acúmulo de MS neste órgão (Figuras 1 e 2).

Nas folhas, houve acúmulo crescente de $\mathrm{Cu}$ até os 80 DAE durante a safra, mas os demais micronutrientes atingiram os valores máximos entre 70 e 75 DAE, coincidindo com o período de máxima MS foliar (Figuras 2b, 3b, 4b, 5b, 6b, 7b e $8 b$ ). Na safrinha, os acúmulos máximos foliares de B, Mn e Mo ocorreram em época semelhante à observada para a maioria dos micronutrientes no cultivo de safra, ou seja, entre 70 e 75 DAE. O Fe e o $\mathrm{Cu}$ foram os micronutrientes que durante a safrinha permaneceram sendo acumulados nas folhas por maior período de tempo, alcançando os acúmulos máximos aos 80 e 90 DAE, respectivamente (Figuras 5 b e 4b). O Zn foi o micronutriente com acúmulo mais precoce nas folhas, durante a safrinha, pois o máximo acúmulo foliar ocorreu aos 55 DAE (Figura 8b). Nas fases finais do ciclo, de ambas as safras, verificou-se redução dos acúmulos foliares dos micronutrientes (Figuras 3b, 4b, 5b, 6b, 7b e 8b), em decorrência da diminuição da MS foliar (Figura 2b). Entretanto, na safrinha, mesmo com a redução na MS foliar na fase final do ciclo, verificou-se que os acúmulos foliares de $\mathrm{Cu}$ permaneceram constantes nessa época (Figuras 2 b e 4b), em decorrência do aumento nos teores foliares (Tabela 2). 
Figura 3. Acúmulo de B no caule (a), folhas (b), estruturas reprodutivas (c), parte aérea (d), e taxas de acúmulo de B nas estruturas reprodutivas (e) e na parte aérea (f) do híbrido de mamona Savana na safra 2005/06 e na safrinha 2006. **: significativo a $1 \%$ de probabilidade pelo teste $\mathrm{F}$.
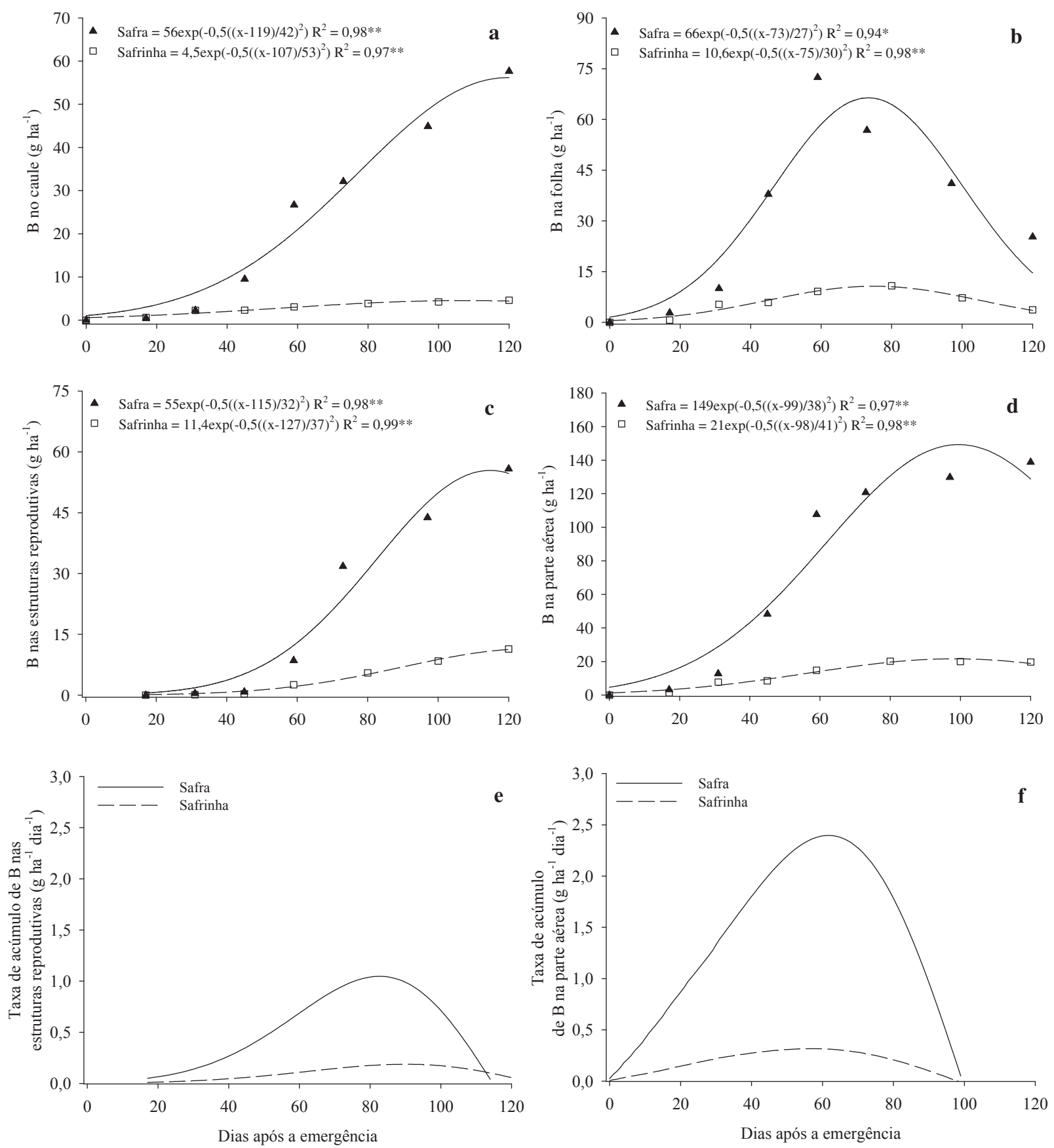

Fonte: Elaboração dos autores. 
Figura 4. Acúmulo de $\mathrm{Cu}$ no caule (a), folhas (b), estruturas reprodutivas (c), parte aérea (d), e taxas de acúmulo de $\mathrm{Cu}$ nas estruturas reprodutivas (e) e na parte aérea (f) do híbrido de mamona Savana na safra 2005/06 e na safrinha 2006. **: significativo a $1 \%$ de probabilidade pelo teste $\mathrm{F}$.
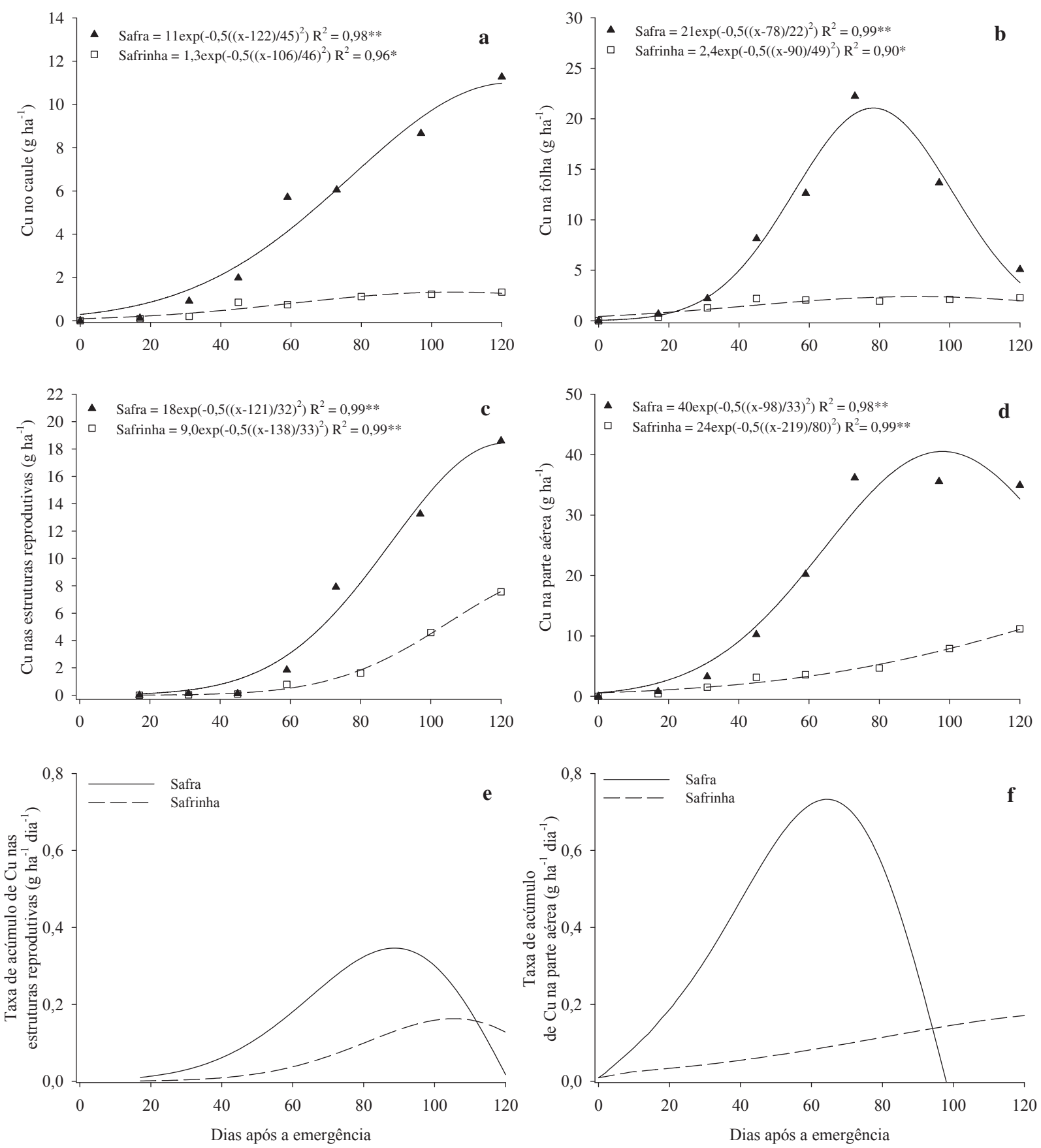

Fonte: Elaboração dos autores. 
Figura 5. Acúmulo de Fe no caule (a), folhas (b), estruturas reprodutivas (c), parte aérea (d), e taxas de acúmulo de $\mathrm{Fe}$ nas estruturas reprodutivas (e) e na parte aérea (f) do híbrido de mamona Savana na safra 2005/06 e na safrinha 2006. **: significativo a $1 \%$ de probabilidade pelo teste $\mathrm{F}$.
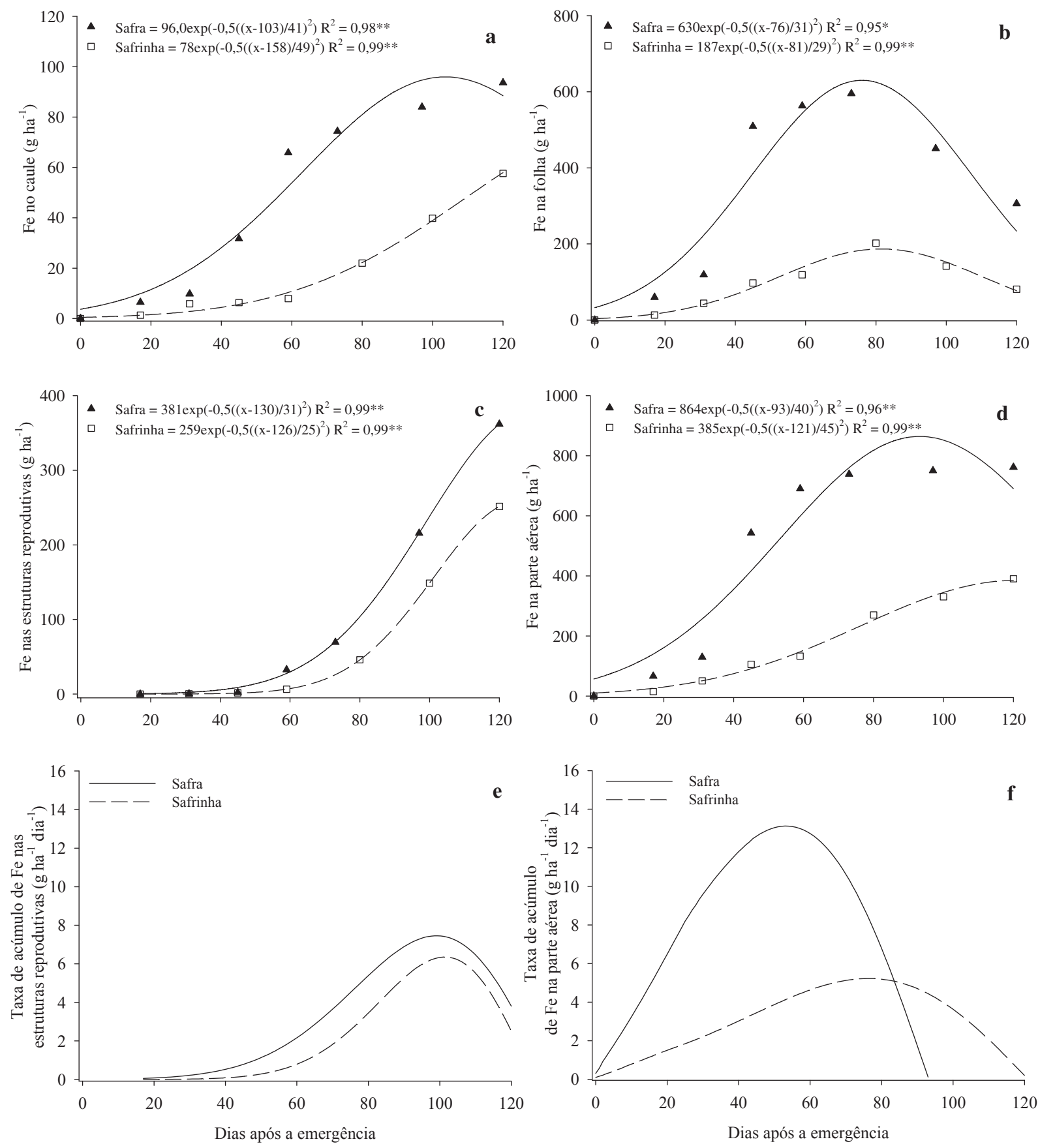

Fonte: Elaboração dos autores. 
Figura 6. Acúmulo de Mn no caule (a), folhas (b), estruturas reprodutivas (c), parte aérea (d), e taxas de acúmulo de Mn nas estruturas reprodutivas (e) e na parte aérea (f) do híbrido de mamona Savana na safra 2005/06 e na safrinha 2006. **: significativo a $1 \%$ de probabilidade pelo teste $\mathrm{F}$.
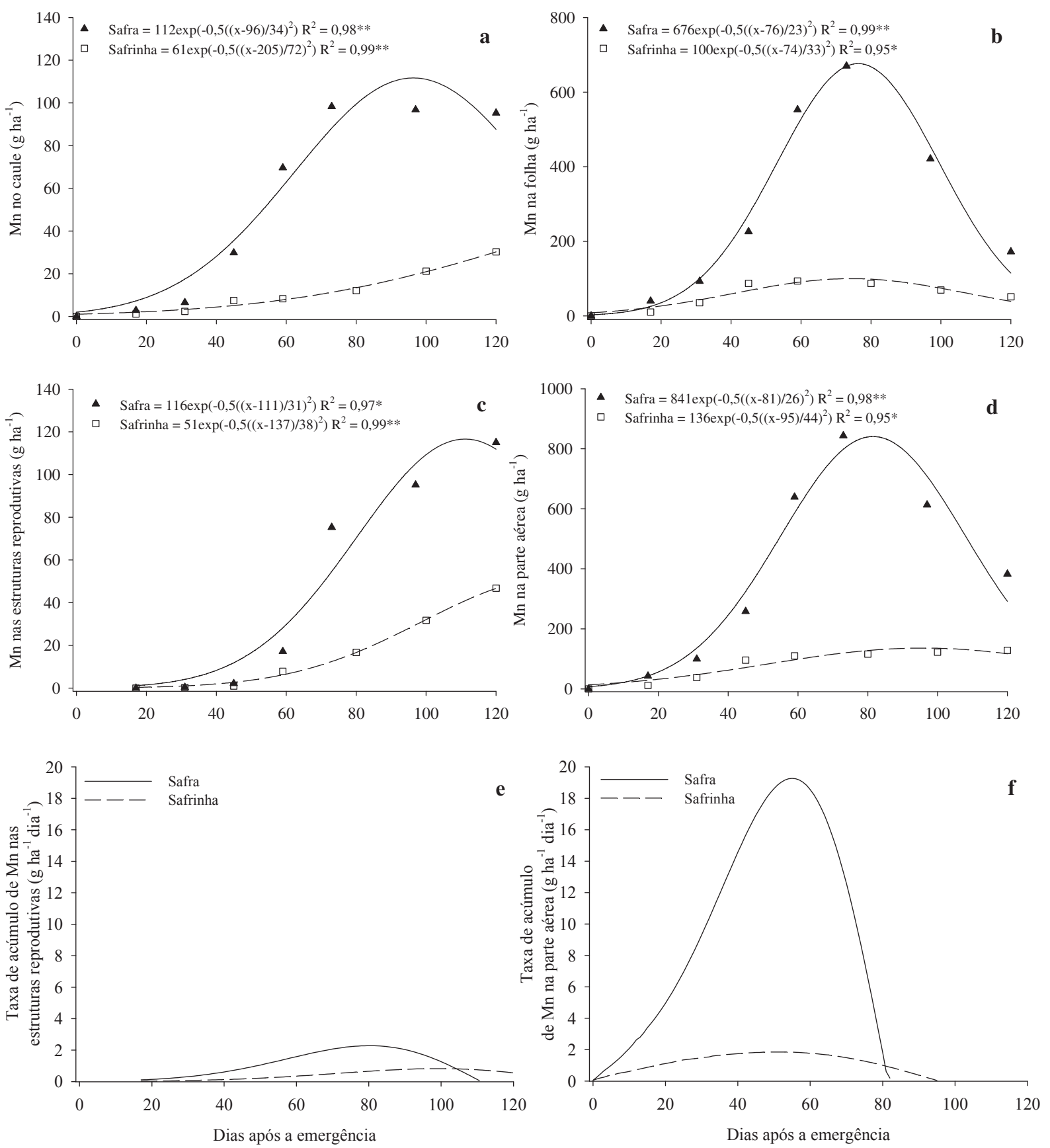

Fonte: Elaboração dos autores. 
Figura 7. Acúmulo de Mo no caule (a), folhas (b), estruturas reprodutivas (c), parte aérea (d), e taxas de acúmulo de Mo nas estruturas reprodutivas (e) e na parte aérea (f) do híbrido de mamona Savana na safra 2005/06 e na safrinha 2006. **: significativo a $1 \%$ de probabilidade pelo teste $\mathrm{F}$.
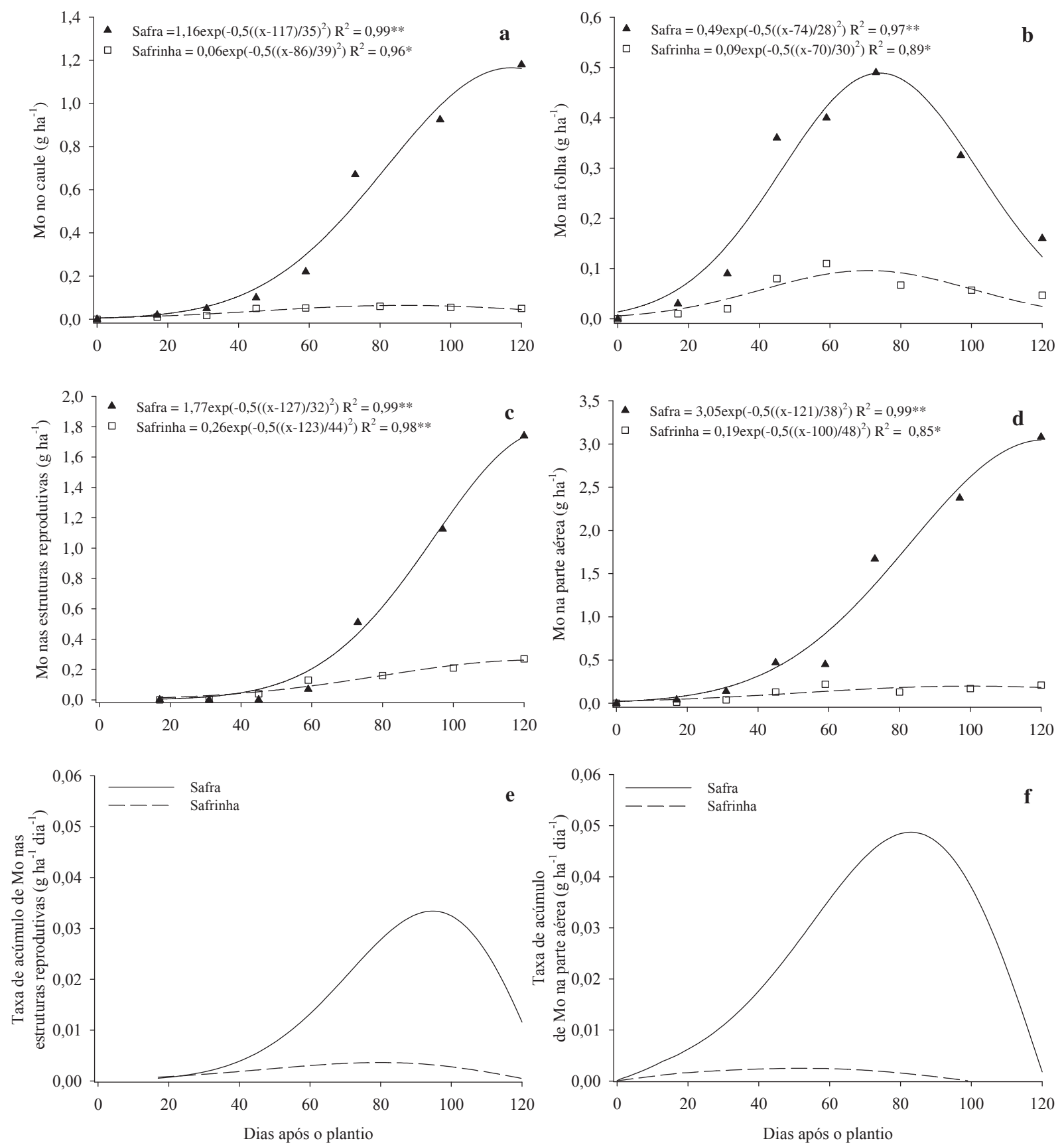

Fonte: Elaboração dos autores. 
Figura 8. Acúmulo de Zn no caule (a), folhas (b), estruturas reprodutivas (c), parte aérea (d), e taxas de acúmulo de Zn nas estruturas reprodutivas (e) e na parte aérea (f) do híbrido de mamona Savana na safra 2005/06 e na safrinha 2006. **: significativo a $1 \%$ de probabilidade pelo teste $\mathrm{F}$.
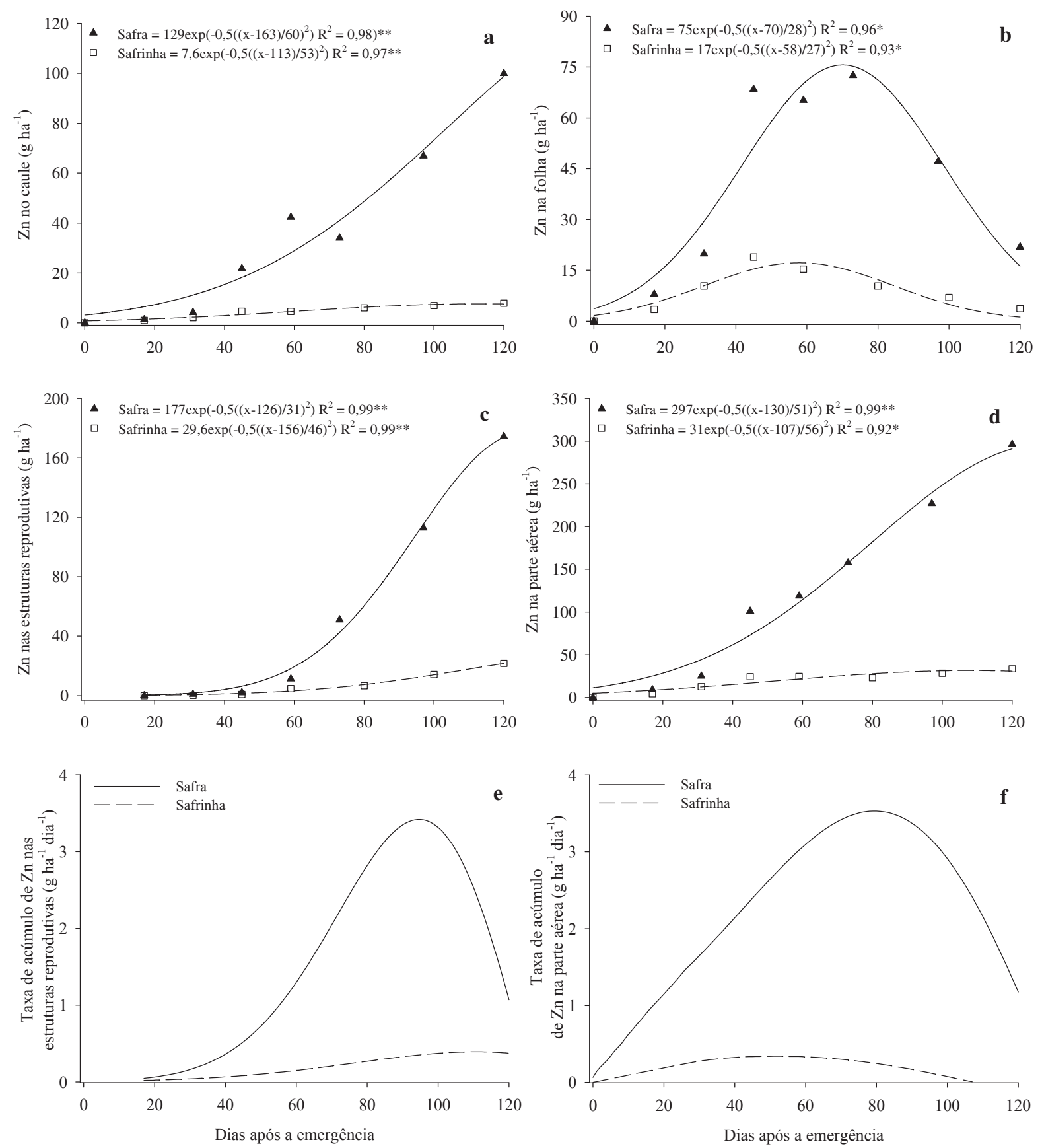

Fonte: Elaboração dos autores. 
Constatou-se que os micronutrientes $\mathrm{B}, \mathrm{Cu}$ e $\mathrm{Mo}$ foram acumulados em quantidades relativamente semelhantes nas folhas e caules durante a safrinha (Figuras 3a, 3b, 4a, 4b, 7a e 7b). Durante a safra, o $\mathrm{Zn}$ e Mo foram acumulados em maiores quantidades nos caules, mas na safrinha o acúmulo foliar de $\mathrm{Zn}$ sobressaiu ao do caule (Figuras 7a, 7b, 8a e 8b). Chaves et al. (2009) estudando o efeito do Zn e Cu no estado nutricional da mamoneira, constataram que os teores de $\mathrm{Zn}$ no caule estiveram, em geral, acima dos teores foliares, sugerindo que o caule acumula maiores quantidades desse elemento que às folhas. Entretanto, verificou-se que o maior acúmulo de $\mathrm{Zn}$ no caule em relação às folhas só ocorre no cultivo de safra, em que as quantidades absorvidas são maiores (Figuras 8a e 8b). Independente da época de cultivo verificou-se maior acúmulo de Fe e Mn nas folhas em comparação ao caule (Figuras 5a, 5b, $6 \mathrm{a}$ e $6 b)$.

As quantidades de $\mathrm{Fe}$ e $\mathrm{Mn}$ acumuladas na parte vegetativa, representada pelas folhas e caule, foram superiores àquelas obtidas nas estruturas reprodutivas, exceto para o Fe na safrinha (Figuras $5 \mathrm{a}, 5 \mathrm{~b}, 5 \mathrm{c}, 6 \mathrm{a}, 6 \mathrm{~b}$ e $6 \mathrm{c})$. Esse padrão de distribuição do Fe e Mn em favor das folhas e caule está relacionado com suas funções no metabolismo da planta. $\mathrm{O} F$ atua na síntese da clorofila, participa da fotossíntese e da respiração (MALAVOLTA, 2006; DECHEN; NACHTIGALL, 2006). Além disso, após absorvido seu transporte à longa distância é feito, via xilema e sua mobilização para dentro do floema é diminuída, pela formação de compostos insolúveis nas folhas (DECHEN; NACHTIGALL, 2006). Por isso, o Fe é acumulado, preferencialmente, nas folhas que é o sítio primário da função desse nutriente (KIRKBY; RÖMHELD, 2007).

O Mn atua como ativador enzimático no processo de respiração e participa da fotólise da água na fotossíntese (MALAVOLTA, 2006). Assim, as maiores quantidades de Mn na parte vegetativa, representada pelas folhas e caule, devem-se a sua pequena redistribuição na planta. Pois, após absorvido, o Mn move-se via corrente transpiratória e acumula-se em certos órgãos da planta como as folhas (MALAVOLTA, 2006), sendo que, o pequeno transporte que ocorre via floema é responsável pela baixa concentração desse elemento em frutos, sementes e órgãos de reserva (DECHEN; NACHTIGALL, 2006). Porém, assim que o Mn é incorporado ou imobilizado nas folhas, não pode mais ser retranslocado, mesmo sob senescência induzida (WOOD et al., 1986).

Esses resultados estão de acordo com os relatados por Hocking (1982) que observou em solos arenosos de baixa fertilidade a remobilização de apenas 18\% do Mn dos frutos para as sementes da mamoneira, enquanto que a remobilização de $\mathrm{Fe}$ dos frutos para as sementes foi praticamente nula, evidenciando assim, que as sementes de mamona acumulam pequenas quantidades desses nutrientes.

Nas estruturas reprodutivas, os acúmulos de micronutrientes aumentaram lentamente desde o florescimento até aos 50 DAE, para depois se intensificar, como observado para a MS (Figuras 2c, $3 c, 4 c, 5 c, 6 c, 7 c$ e 8c). Com exceção do B e Mn no período de safra, os demais micronutrientes foram acumulados até o final do ciclo.

A acumulação de micronutrientes nas estruturas reprodutivas resultou num padrão bem definido, em ambas as safras, com taxas de acúmulo muito baixas nos primeiros 20 dias após o florescimento e com maiores taxas de acumulação entre 80 e 100 DAE (Figuras 3e, 4e, 5e, 6e, 7e e 8e). Verificou-se que os acúmulos de micronutrientes nas estruturas reprodutivas durante a safra, foram superiores aos da safrinha (Figuras 3c, 4c, 5c, 6c, 7c e 8c), em função da maior disponibilidade hídrica, que proporcionou maior acúmulo de MS (Figuras 1 e 2c) e maiores taxas de acumulação de micronutrientes nestes órgãos (Figuras 3e, 4e, 5e, 6e, 7e e 8e). Porém, apenas os acúmulos de $\mathrm{Fe}$ nas estruturas reprodutivas variaram pouco entre as safras estudadas (Figura $5 \mathrm{c}$ ), o que é reflexo dos maiores teores de Fe entre os 80 e 100 DAE do cultivo de safrinha (Tabela 2), uma vez que a MS acumulada neste órgão durante a safrinha foi menor (Figura 2c). 
Na parte aérea, os acúmulos de micronutrientes foram pequenos até o início do florescimento, exceto para o acúmulo de Fe, no período de safra, que foi crescente desde a emergência (Figuras 3d, 4d, 5d, 6d, 7d e 8d). Esse maior acúmulo de Fe nas fases iniciais do período de safra é reflexo dos maiores teores desse elemento nas folhas e caule (Tabelas 1 e 2), ocasionados, possivelmente pela maior disponibilidade hídrica (Figura 1) e maior teor no solo (42 $\mathrm{mg} \mathrm{dm}^{-3}$ ). As quantidades de micronutrientes extraídas do solo diferiram entre as safras, indicando que as exigências nutricionais desse híbrido variam, dependendo da época de cultivo. Os acúmulos de Mo e $\mathrm{Zn}$, na safra, e de $\mathrm{Cu}$ e Fe, na safrinha, aumentaram desde o florescimento até o final do ciclo (Figuras $4 d, 5 d, 7 d$ e $8 d$ ). Os micronutrientes $\mathrm{B}$, em ambas as safras, $\mathrm{Cu}$ no cultivo de safra, e Mo e Zn no período de safrinha também foram mais intensamente acumulados após o florescimento, no entanto, as plantas absorveram as quantidades totais até os $100 \mathrm{DAE}$, período em que as taxas de absorção tornaram-se nulas (Figuras 3d, 3f, 4d, 4f, 7d, 7f, 8d e 8f). Já o Mn em ambas as safras e o Fe no período de safra atingiram os acúmulos máximos aos 80 e 95 DAE, ou seja, quando as taxas de acúmulo atingiram os valores mínimos e as quantidades acumuladas nas plantas passaram a diminuir (Figuras 5d, 5f, 6d e 6f) em função, principalmente, da redução da MS foliar (Figura 2b).

Os períodos de maior demanda por micronutrientes ocorreram na mesma época para o Mo e Zn na safra e para o Fe na safrinha, ou seja, por volta dos 80 DAE (Figuras 5f, 7f e 8f). Para o B e o $\mathrm{Cu}$ as maiores demandas no período de safra foram observadas entre 60 e 65 DAE (Figuras 3f e 4f). Já os micronutrientes B, Mo e Zn na época de safrinha, o Mn em ambas as safras, e o Fe no cultivo de safra foram absorvidos em maiores taxas por volta dos 50 DAE (Figuras 3f, 5f, 6f, 7f e 8f). Porém, o $\mathrm{Cu}$ no cultivo de safrinha foi o único micronutriente que foi absorvido em taxas crescentes até o final do ciclo (Figuras 4f).
A extração máxima de micronutrientes ocorreu na seguinte seqüência em ambas as safras: $\mathrm{Fe}>\mathrm{Mn}>\mathrm{Zn}>\mathrm{B}>\mathrm{Cu}>\mathrm{Mo}$. Porém as quantidades extraídas por hectare no cultivo de safra foram de $864 \mathrm{~g}$ de Fe, $840 \mathrm{~g}$ de Mn, $295 \mathrm{~g}$ de Zn, 150 $\mathrm{g}$ de $\mathrm{B}, 41 \mathrm{~g}$ de $\mathrm{Cu}$ e 3,0 g de Mo, enquanto que na safrinha, a extração foi de 390, 137, 32, 22, 11 e $0,21 \mathrm{~g} \mathrm{ha}^{-1}$, respectivamente, de Fe, Mn, Zn, B, Cu e Mo (Figuras 1d, 2d, 3d, 4d, 5d e 6d). A maior absorção de Fe e Mn é reflexo das taxas de acúmulo superiores as dos demais micronutrientes, bem como dos maiores teores desses elementos nos tecidos (Figuras 3d, 3f, 4d, 4f e Tabelas 1 e 2). Lange et al. (2005) observaram em plantas de mamona, cultivadas em solução nutritiva, que os primeiros sintomas de deficiência ocorreram no tratamento com omissão de Fe e Mn, indicando a maior exigência desses micronutrientes.

Embora os teores nos grãos de praticamente todos os micronutrientes tenham sido maiores no cultivo de safrinha, a exportação por área foi maior no cultivo de safra, em que produtividade de grãos foi maior (Tabela 3). Na safra, a ordem de exportação de micronutrientes foi $\mathrm{Fe}>\mathrm{Zn}>\mathrm{Mn}>\mathrm{B}>\mathrm{Cu}>\mathrm{Mo}$, mas na safrinha o $\mathrm{Mn}$ foi mais exportado que o $\mathrm{Zn}$, e o $\mathrm{Cu}$ não diferiu do $\mathrm{B}$ (Tabela 3 ).

Houve grande variação nas quantidades de micronutrientes extraídas e exportadas por área entre as safras (Figuras 3d, 4d, 5d, 6d, 7d, 8d e Tabela 3), porém, a extração e exportação por tonelada de grãos, embora tenha variado, resultou em valores menos discrepantes entre as épocas de cultivo (Tabela 3).

Verificou-se que das quantidades totais acumuladas pelas plantas por volta de $50 \%$ do $\mathrm{Zn}$, independente da safra, e $60 \%$ do $\mathrm{Cu}$ absorvido no cultivo de safrinha foram exportados com os grãos. Para os demais micronutrientes a proporção exportada com os grãos foi inferior a $40 \%$ do total absorvido, evidenciando que do total acumulado nas plantas ao longo do ciclo, grande parte retorna ao solo com os restos culturais. 
Tabela 3. Teor nos grãos, exportação por área, extração e exportação por tonelada de grãos, e exportação relativa de micronutrientes pelo híbrido de mamona Savana na safra 2005/06 e na safrinha 2006.

\begin{tabular}{|c|c|c|c|c|c|c|}
\hline Época de cultivo & $\mathrm{B}$ & $\mathrm{Cu}$ & $\mathrm{Fe}$ & $\mathrm{Mn}$ & Mo & $\mathrm{Zn}$ \\
\hline & \multicolumn{6}{|c|}{ Teor nos grãos $\left(\mathrm{mg} \mathrm{kg}^{-1}\right)$} \\
\hline Safra & 10,9 & 5,6 & 134,0 & 37,3 & 0,32 & 58,0 \\
\hline \multirow[t]{2}{*}{ Safrinha } & 13,6 & 13,8 & 305,0 & 88,2 & 0,04 & 35,4 \\
\hline & \multicolumn{6}{|c|}{ Exportação por área $\left(\mathrm{g} \mathrm{ha}^{-1}\right)$} \\
\hline Safra & 28,2 & 14,4 & 346,0 & 96,3 & 0,83 & 149,7 \\
\hline \multirow[t]{2}{*}{ Safrinha } & 6,7 & 6,8 & 150,7 & 43,6 & 0,017 & 17,5 \\
\hline & \multicolumn{6}{|c|}{ Extração por tonelada de grãos ( $\mathrm{g} \mathrm{t}^{-1}$ de grãos produzidos) ${ }^{(1)}$} \\
\hline Safra & 58,1 & 15,9 & 334,6 & 325,3 & 1,16 & 114,3 \\
\hline \multirow[t]{2}{*}{ Safrinha } & 44,5 & 22,3 & 789,4 & 277,3 & 0,38 & 64,8 \\
\hline & \multicolumn{6}{|c|}{ Exportação por tonelada de grãos ( $\mathrm{g} \mathrm{t}^{-1}$ de grãos produzidos) } \\
\hline Safra & 10,9 & 5,6 & 134,0 & 37,3 & 0,32 & 58,0 \\
\hline \multirow[t]{2}{*}{ Safrinha } & 13,6 & 13,8 & 305,0 & 88,3 & 0,03 & 35,4 \\
\hline & \multicolumn{6}{|c|}{ Exportação relativa pelos grãos $(\%)^{(2)}$} \\
\hline Safra & 18,8 & 35,1 & 40,0 & 11,5 & 27,7 & 50,7 \\
\hline Safrinha & 30,5 & 61,8 & 38,6 & 31,8 & 8,9 & 54,7 \\
\hline
\end{tabular}

\section{Conclusões}

Em ambas as safras a ordem de extração de micronutrientes pelo híbrido Savana é: $\mathrm{Fe}>\mathrm{Mn}>\mathrm{Zn}>\mathrm{B}>\mathrm{Cu}>\mathrm{Mo}$, mas com quantidades maiores no cultivo de safra. A época de maior absorção de Mo e Zn durante a safra e de Fe na safrinha ocorre aos 80 DAE, porém os demais micronutrientes são absorvidos em maiores taxas entre os 50 e 65 DAE. Na safra a produtividade de grãos, a extração e a exportação de nutrientes do solo é maior, mas a extração e exportação por tonelada de grãos apresenta menor variação entre as épocas de cultivo. Em média 50\% do Zn absorvido ao longo do ciclo e $60 \%$ do $\mathrm{Cu}$ extraído na safrinha são exportados com os grãos, mas para os demais micronutrientes a proporção exportada é inferior a $40 \%$.

\section{Referências}

CANECCHIO FILHO, V.; FREIRE, E. S. Adubação da mamoneira: experiências preliminares. Bragantia, Campinas, v. 17, n. 19, p. 243-259, 1958.
CHAVES, L. H. G.; CABRAL, P. C. P.; BARROS JÚNIOR, G.; LACERDA, R. D. Efeito de zinco e cobre no estado nutricional da mamoneira, BRS 188 Paraguaçú. Revista Caatinga, Mossoró, v. 22, n. 4, p. 129-135, 2009.

DANTAS JÚNIOR, E. E.; CHAVES, L. H. G.; COSTA, F. A. M.; MESQUITA, E. F.; ARAÚJO, D. L. Crescimento de duas cultivares de mamoneira adubadas com potássio, cobre e zinco. Revista Caatinga, Mossoró, v. 23, n. 4, p. 97-107, 2010.

DECHEN, A. R.; NACHTIGALL, G. R. Micronutrientes. In: FERNANDES, M. S. (Ed.). Nutrição mineral de plantas. Viçosa, MG: SBCS, 2006. p. 328-352.

DORDAS, C.; SAH, R.; BROWN, P. H.; ZENG, Q.; HU, H. Remobilização de micronutrientes e elementos tóxicos em plantas superiores. In: FERREIRA, M. E.; CRUZ, M. C. P.; RAIJ, B. van; ABREU, C. A. (Ed.). Micronutrientes e elementos tóxicos na agricultura. Jaboticabal: CNPQ/FAPESP/POTAFOS, 2001. p. 43-69.

FERREIRA, M. M. M.; FERREIRA, G. B.; SANTOS, A. C. M.; XAVIER, R. M.; SEVERINO, L. S.; BELTRÃO, N. E. M.; DANTAS, J. P.; MORAES, C. R. A. Deficiência de enxofre e efeito sobre o crescimento e a produção da cultura. In: CONGRESSO BRASILEIRO DE MAMONA, 1., 2004. Campina Grande. Anais... Campina Grande: Embrapa Algodão, 2004. CD-ROM. 
HOCKING, P. J. Accumulation and distribution of nutrients in fruits of castor bean (Ricinus communis L.). Annals of Botany, Oxford, v. 49, n. 1, p. 51-62, 1982.

KIRKBY, E. A.; RÖMHELD, V. Micronutrientes na fisiologia de plantas: funções, absorção e mobilidade. Piracicaba: IPNI, 2007. 24 p. (Encarte de Informações Agronômicas, n. 118).

LANGE, A.; MARTINES, A. M.; SILVA, M. A. C.; SORREANO, M. C. M.; CABRAL, C. P.; MALAVOLTA, E. Efeito de deficiência de micronutrientes no estado nutricional da mamoneira cultivar 'Iris'. Pesquisa Agropecuária Brasileira, Brasília, v. 40, n. 1, p. 61-67, 2005 .

MALAVOLTA, E. Elementos de nutrição mineral de plantas. São Paulo: Agronômica Ceres, 1980. 251 p.

. Manual de nutrição mineral de plantas. São Paulo: Agronômica Ceres, 2006. 638 p.

MALAVOLTA, E.; VITTI, G. C.; OLIVEIRA, S. A. Avaliação do estado nutricional de plantas: princípios e aplicações. 2. ed. Piracicaba: Potafós, 1997. 308 p.

NAKAGAWA, J.; NEPTUNE, A. M. L. Marcha de absorção de nitrogênio, fósforo, potássio, cálcio e magnésio na cultura da mamoneira (Ricinus communis L.) cultivar Campinas. Anais da Escola Superior de Agricultura Luiz de Queiroz, Campinas, v. 28, 1971. p. 323-337.

ORLANDO FILHO, J.; ROSSETTO, R.; CASAGRANDE, A. A. Cana-de-açúcar. In: FERREIRA, M. E.; CRUZ, M. C. P.; RAIJ, B. Van; ABREU, C. A. (Ed.). Micronutrientes e elementos tóxicos na agricultura. Jaboticabal: CNPQ/FAPESP/POTAFOS, 2001. p. 355-369.

PAUlO, E. M.; BATAGLIA, O. C.; KASAI, F. S.; CAVICHIOLI, J. C. Deficiência de boro em mamona. Bragantia, Campinas, v. 48, n. 2, p. 241-247, 1989.

RAIJ, B. Van; ANDRADE, J. C.; CANTARELLA, H.; QUAGGIO, J. A. Análise química para avaliação da fertilidade de solos tropicais. Campinas: Instituto Agronômico, 2001. 284 p.
SANTOS, A. C. M.; FERREIRA, G. B.; XAVIER, R. M.; FERREIRA, M. M. M.; SEVERINI, L. S.; BELTRÃO, N. E. M.; DANTAS, J. P.; MORAES, C. R. A. Deficiência de cálcio e magnésio na mamona (Ricinus communis L.): descrição e efeito sobre o crescimento e a produção da cultura. In: CONGRESSO BRASILEIRO DE MAMONA, 1., 2004. Campina Grande. Anais.... Campina Grande: Embrapa Algodão, 2004. CD-ROM.

SAVY FILHO, A.; BANZATO, N. V.; BARBOZA, M. Z.; MIGUEL, A. M. R. O.; DAVI, L. O. C.; RIBEIRO, F. M. Mamona: In: COORDENADORIA DE ASSISTÊNCIA TÉCNICA INTEGRAL - CATI. Oleaginosas no estado de São Paulo: análise e diagnóstico. Campinas: CATI. 1999. 39 p. (Documento técnico, 107).

SEVERINO, L. S.; FERREIRA, G. B.; MORAES, C. R. A.; GONDIM, T. M. S.; FREIRE, W. S. A.; CASTRO, D. A.; CARDOSO, G. D.; BELTRÃO, N. E. M. Crescimento e produtividade da mamoneira adubada com macronutrientes e micronutrientes. Pesquisa Agropecuária Brasileira, Brasília, v. 41, n. 4, p. 563-568, 2006.

SILVA, A. G.; CRUSCIOL, C. A. C.; SORATTO, R. P.; COSTA, C. H. M.; FERRARI NETO, J. Produção de fitomassa e acúmulo de nutrientes por plantas de cobertura e cultivo da mamona em sucessão no sistema plantio direto. Ciência Rural, Santa Maria, v. 40, n. 10, p. 2092-2098, 2010.

SOUZA, E. C. A.; NATALE, W. Efeito do boro e do zinco na cultura da mamoneira. Científica, São Paulo, v. 25, n. 2, p. 327-333, 1997.

TAIZ, L.; ZEIGER, E. Fisiologia vegetal. 3. ed. Porto Alegre: Artmed, 2004. 719 p.

WOOD, L. J.; MURRAY, B. J.; OKATAN, Y.; NOODÉN, L. D. Effect of petiole phloem distribution on starch and mineral distribution in senescing soybean leaves. American Journal of Botany, Bronx, v. 73, n. 10, p. $1377-$ 1383, 1986. 
